\title{
A green route to high-surface area carbons by chemical activation of biomass-based products with sodium thiosulfate
}

\author{
Antonio B. Fuertes ${ }^{\star}$, Guillermo A. Ferrero, Noel Diez and Marta \\ Sevilla
}

Instituto Nacional del Carbón (CSIC), Fco. Pintado Fe 26, Oviedo 33011, Spain

*Corresponding author: abefu@incar.csic.es

\begin{abstract}
A simple, sustainable and affordable approach for the synthesis of highly porous carbons is presented. The procedure is based on the use of sodium thiosulfate as an activating agent and a variety of biomass-based products (glucose, sucrose and gelatine) as carbon precursors. The synthesis scheme involves three steps: a) mixing the reactants by grinding, b) heat treatment at temperatures in the 800-900 ${ }^{\circ} \mathrm{C}$ range and c) extracting the carbon material from the carbonised solid by simple washing with water. The generation of the pore structure is based on the redox reaction between the carbonaceous matter and sodium thiosulfate acting as an oxidant. In this way, porous carbons with high BET surface areas in the $\sim 2000-2700 \mathrm{~m}^{2} \mathrm{~g}^{-1}$ range and large pore volumes of up to $2.4 \mathrm{~cm}^{3} \mathrm{~g}^{-1}$ are obtained. The porosity of these carbons consists of two pore systems made up of narrow micropores of $0.8 \mathrm{~nm}$ and larger pores of up to $5 \mathrm{~nm}$. These porous carbons have a certain amount of sulfur $(\sim 2-3 \%)$ that is incorporated into the carbon framework as thiophene-like and oxidised sulfur groups. Additionally, in the case of gelatine, $\mathrm{N}$ content up to $2-3 \%$ is preserved.
\end{abstract}

Keywords: Biomass, sodium thiosulfate, chemical activation, porous carbon, high surface area, sulfur doping, N-doped carbon 


\section{Introduction}

The design of new synthesis strategies for the production of porous carbons has generated growing interest owing to the use of this type of material in several emergent areas such as adsorbents for gas storage (e.g. $\mathrm{H}_{2}, \mathrm{CH}_{4}$, $\left.\mathrm{CO}_{2}\right){ }^{1-4}$ as catalysts or catalytic supports in fuel cells ${ }^{5-7}$ and as electrode components in energy storage systems (e.g. supercapacitors and Li-ion batteries). ${ }^{8-11}$ The importance of porous carbons lies in the fact that they exhibit several significant properties: a) a high surface area and porosity able to store large amounts of a variety of substances (e.g. gases, ions or elements such as sulfur and selenium), b) high chemical stability that allows them to operate in corrosive environments, c) good electrical conductivity which is especially important for electrochemical applications, and d) low cost and high availability 12, 13. These materials are produced from a large variety of substances (e.g. biomass, coal or petroleum by-products, polymers or simple organic compounds) and are usually produced by using one of two synthesis strategies based on the oxidation of carbon: a) physical activation consisting of the gassolid reaction between a carbonised precursor and a reactive gas (e.g. steam, $\mathrm{CO}_{2}$ or air) or b) chemical activation involving a solid-solid reaction between the carbon precursor and certain chemical agents such as alkali hydroxides/carbonates, phosphoric acid or zinc chloride. ${ }^{14-17}$ While physical activation gives rise to carbons with a porosity made up almost exclusively of micropores $<2 \mathrm{~nm}$, chemical activation is more versatile allowing the production of materials with a larger surface area and pore volumes, with a more open and tuneable porosity made up of micropores and small mesopores. ${ }^{18}$ Carbon materials with this pore structure are important for applications that not only 
require simple storage of substances, but also fast mass transport rates from/towards the pore network. These characteristics are especially important in the case of using carbon as an electrode in electrochemical systems such as supercapacitors or lithium batteries..$^{3,19-21}$ Thus, for example, porous carbons with a high pore volume and accessible porosity are essential for the fabrication of the cathode in Li-S batteries because they can improve the conductivity of the electrode and also serve as store for a large amount of sulfur, accommodate the volume expansion and trap a portion of the dissolved polysulfides. ${ }^{22-25}$ In this context, the use of chemical agents to produce porous carbons with these characteristics has attracted much attention and in recent years a huge number of studies have been published in this area. Potassium hydroxide is the most popular activating agent, but other chemical substances are also employed to this end (e.g. $\mathrm{NaOH}, \mathrm{H}_{3} \mathrm{PO}_{4}$ or $\mathrm{ZnCl}_{2}$ ), all of which present serious economic and environmental problems owing to their high corrosiveness and toxicity, making it necessary to use protective measures and expensive reactors. For these reasons, the development of alternative synthesis routes for chemical activation based on harmless substances is an important objective. Several authors have explored the use as activating agents of several less-corrosive potassium chemical compounds such as potassium carbonate, 26-29 potassium bicarbonate ${ }^{30,31}$ and potassium oxalate, ${ }^{32-34}$ which have proven to be able to produce highly porous carbons. In spite of these advances the formation of potassium as a consequence of the activation process constitutes a serious drawback (i.e. risk of explosion/flames). It seems clear that it is important to design simpler and greener synthesis routes, which should be based on sustainable and economical carbon precursors (i.e. biomass-based 
products and sub-products) and on the use of harmless activating chemical agents that minimise the generation of risky sub-products. We recently demonstrated an example of this synthesis strategy by showing that the simple carbonisation of calcium citrate leads to a highly mesoporous carbon with calcium oxide as the only sub-product generated. ${ }^{35-37}$

In this study, we present a synthesis procedure for highly porous carbons based on the use of a harmless inorganic compound such as sodium thiosulfate $\left(\mathrm{Na}_{2} \mathrm{~S}_{2} \mathrm{O}_{3}\right)$ as an activating agent. In an earlier study, Liu and Antonietti reported the preparation of high-surface area carbons via the carbonisation of a mixture of glucose and sodium thiosulfate in a eutectic medium $(\mathrm{LiCl} / \mathrm{KCl}){ }^{38}$ This constituted the first demonstration of the activating capacity of $\mathrm{Na}_{2} \mathrm{~S}_{2} \mathrm{O}_{3}$ and the authors ascribed it to the special conditions provided by the eutectic reaction medium. However, in our study, we demonstrate that $\mathrm{Na}_{2} \mathrm{~S}_{2} \mathrm{O}_{3}$ can be considered an all-purpose activating agent, not limited to the use of a eutectic reaction medium, and that it is effective for the activation of a variety of precursors under different operational conditions. This finding opens the door to a novel green route for the preparation of highly porous carbons based on the use of a harmless activating agent. In this study, we apply this synthesis strategy to the production of highly porous carbons from three biomass-based products; glucose, sucrose and gelatine.

\section{Experimental}

Synthesis of porous carbon

In a typical synthesis procedure, $3 \mathrm{~g}$ of carbon precursor (gelatine, sucrose or glucose from Aldrich) was mixed by grinding with $10 \mathrm{~g}$ of potassium chloride (Aldrich) and between 2 and $4 \mathrm{~g}$ of sodium thiosulfate (Alfa-Aesar). The 
powder was heated under $\mathrm{N}_{2}$ to the desired temperature (i.e. 800 or $900^{\circ} \mathrm{C}$ ) at a heating rate of $5^{\circ} \mathrm{C} \min ^{-1}$ and held at this temperature for $1 \mathrm{~h}$. Finally, the carbonised solid was washed with distilled water for several hours, the carbon particles were collected by filtration and dried at $120^{\circ} \mathrm{C}$. The carbon samples synthesised at a $\left(\mathrm{Na}_{2} \mathrm{~S}_{2} \mathrm{O}_{3}\right.$ /precursor) weight ratio of 0.67 were labelled $\mathrm{GUK}-\mathrm{X}$, SUK-X or GEK-X for glucose, sucrose and gelatine respectively, where $\mathrm{X}$ was the reaction temperature (800 or $900^{\circ} \mathrm{C}$ ). In the case of gelatine, samples were also prepared at other $\left(\mathrm{Na}_{2} \mathrm{~S}_{2} \mathrm{O}_{3}\right.$ /precursor) weight ratios of 1 (GEK-800-1) and 1.3 (GEK-800-1.3). In addition, a carbon sample, labelled GEK-800-1.3-L, was prepared by freeze-drying a solution of the reaction ingredients. Certain samples synthesised without $\mathrm{KCl}$ (for comparison purposes) were labelled GU800 and GE-800 for glucose and gelatine respectively.

\section{Physicochemical Characterisation}

Scanning electron microscopy (SEM) images were obtained on a Quanta FEG650 (FEI) instrument, while transmission electron microscopy (TEM) images were recorded using JEOL (JEM 2100-F) apparatus operating at $200 \mathrm{kV}$. The nitrogen sorption isotherms of the carbon samples were measured at 196드 ${ }^{\circ}$ using a Micromeritics ASAP 2020 sorptometer. The apparent surface area was calculated by the BET method. An appropriate relative pressure range was selected to ensure a positive line intersect of multipoint BET fitting $(C>0)$. The total pore volume was determined from the amount of nitrogen adsorbed at a relative pressure $(\mathrm{P} / \mathrm{P} 0)$ of 0.99 . The pore size distributions (PSD) were determined by means of the Quench Solid State Density Functional Theory (QSDFT) method for nitrogen assuming a slit-like pore shape. X-ray diffraction (XRD) patterns were produced using a Siemens D5000 instrument operating at 
$40 \mathrm{kV}$ and $20 \mathrm{~mA}$, using a $\mathrm{Cu}-\mathrm{K} \alpha$ radiation source. X-ray photoelectron spectroscopy (XPS) was carried out on a Specs spectrometer, using Mg Ka $(1253.6 \mathrm{eV})$ radiation from a double anode at $150 \mathrm{~W}$. Binding energies for the high resolution spectra were calibrated by setting $\mathrm{C}$ 1s to $284.5 \mathrm{eV}$. Deconvolution of the S2p spectrum was performed considering a separation between peaks in each of the doublets of $\sim 1.2 \mathrm{eV}$ and taking into account that the ratio of areas between the spin-up state, $\mathrm{j}_{3 / 2}$, and the spin-down state, $\mathrm{j}_{1 / 2}$, is equal to 2. The elemental analysis of the samples was carried out on a LECO CHN-932 microanalyser. Thermogravimetric analysis (TGA) curves were recorded on a TA Instruments Q6000 TGA system (5ㅇ $\mathrm{C} \mathrm{min}^{-1}-850 \stackrel{\circ}{\circ} \mathrm{C}$ under $\mathrm{N}_{2}$ ). Temperature programmed desorption (TPD) experiments were performed on a Micromeritics Autochem II 2920 coupled to a Pfeiffer-Vacuum Omnistar quadrupole mass spectrometer (5ㅇ $\mathrm{C} \mathrm{min}^{-1}-900 \stackrel{\circ}{ } \mathrm{C}$ under $\mathrm{Ar}$ ). The evolution of $\mathrm{CO}(\mathrm{m} / \mathrm{z}=28)$ and $\mathrm{CO}_{2}(\mathrm{~m} / \mathrm{z}=44)$ was recorded.

\section{Results and Discussion}

\section{Investigation of the mechanism of activation}

In essence, an activation process consists of the weakly bonded carbon atoms in a piece of carbonaceous matter reacting with an oxidising agent. In this process, the carbon which reacts is released as $\mathrm{CO}$ or $\mathrm{CO}_{2}$ and, as a consequence of this carbon loss, a great number of voids (pores) appear in the residual carbonaceous solid. As previously indicated, in the chemical activation process these oxidising agents are certain inorganic compounds, and several reactive gases $\left(\mathrm{CO}_{2}\right.$, steam, etc.) in the case of physical activation. The chemical activating action of inorganic compounds is essentially based on the high-temperature redox reactions that occur between carbon and certain oxysalt 
anions $\left(\mathrm{OH}^{-}, \mathrm{CO}_{3}{ }^{2-}, \mathrm{PO}_{4}^{3-}, \mathrm{NO}_{3}^{-}\right.$, etc. $) .{ }^{39-41} \mathrm{~A}$ typical example is the hightemperature reaction between carbon and carbonate anion,

$$
\mathrm{CO}_{3}^{2-}+\mathrm{C} \rightarrow 2 \mathrm{CO}+\mathrm{O}^{2-}
$$

This type of reaction does not exclude other secondary processes that can contribute to the generation of porosity. Some of these processes include: i) the gasification of carbon by $\mathrm{CO}_{2}$ produced under certain conditions, ii) the reduction of oxides by carbon (i.e. $\mathrm{K}_{2} \mathrm{O}+\mathrm{C}=\mathrm{CO}+2 \mathrm{~K}$ ), iii) the intercalation of certain metallic species (i.e. K) within the carbon layers and iv) the catalytic effects associated with the cations, which are particularly significant in the case of potassium. ${ }^{14}$

Besides the aforementioned oxyanions, sulfate is also able to oxidise carbon at high temperatures as proved by a simple thermodynamic analysis. This is illustrated in Figure 1 by the Ellingham diagram, which shows the change of the standard free energies of the reactions with temperature:

$$
\begin{aligned}
& 2 \mathrm{C}+\mathrm{O}_{2} \rightarrow 2 \mathrm{CO} \\
& \mathrm{C}+\mathrm{O}_{2} \rightarrow \mathrm{CO}_{2} \\
& 0.5 \mathrm{Na}_{2} \mathrm{~S}+\mathrm{O}_{2} \rightarrow 0.5 \mathrm{Na}_{2} \mathrm{SO}_{4}
\end{aligned}
$$

The Ellingham diagram shows that for temperatures $>342{ }^{\circ} \mathrm{C}$, the oxidation of carbon by sodium sulfate to $\mathrm{CO}_{2}$ can take place according to the reaction

$$
\mathrm{Na}_{2} \mathrm{SO}_{4}+2 \mathrm{C} \rightarrow \mathrm{Na}_{2} \mathrm{~S}+2 \mathrm{CO}_{2}
$$

and, at temperatures higher than $520^{\circ} \mathrm{C}$, the following reaction is also feasible

$$
\mathrm{Na}_{2} \mathrm{SO}_{4}+4 \mathrm{C} \rightarrow \mathrm{Na}_{2} \mathrm{~S}+4 \mathrm{CO}
$$




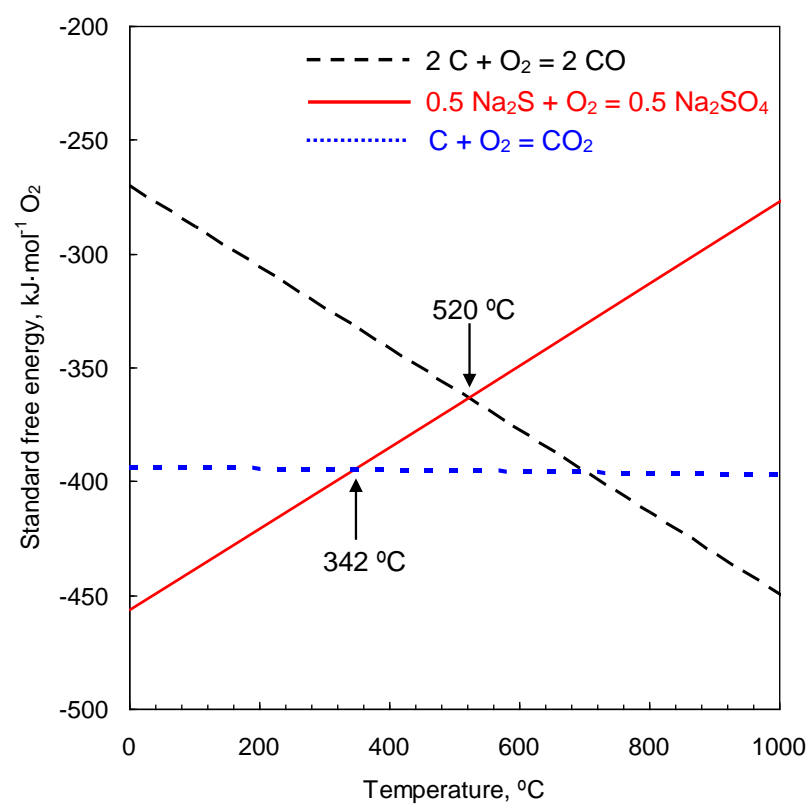

Figure 1. Change with temperature of the standard free energies (Ellingham diagram) of formation of $\mathrm{CO}$ and $\mathrm{CO}_{2}$, and oxidation of sodium sulfide to sodium sulfate.

This simple thermodynamic analysis allows us to establish that: a) carbon can be oxidised by sodium sulfate at temperatures above $\sim 340^{\circ} \mathrm{C}$, b) both $\mathrm{CO}$ and $\mathrm{CO}_{2}$ can be generated as a consequence of the oxidation reactions, and c) the solid residue will be made up of unreacted carbon and sodium sulfide.

In our experiments, we used sodium thiosulfate rather than sodium sulfate as the activating agent since we have found that it gives rise to higher carbon yields and better textural properties. These conclusions can be clearly inferred from the data shown in Table S1. It is well established that on heating at temperatures $>250{ }^{\circ} \mathrm{C}$, sodium thiosulfate decomposes to sodium sulfate and sodium polysulfide:

$$
4 \mathrm{Na}_{2} \mathrm{~S}_{2} \mathrm{O}_{3} \rightarrow 3 \mathrm{Na}_{2} \mathrm{SO}_{4}+\mathrm{Na}_{2} \mathrm{~S}_{5}
$$

The sodium sulfate thus generated becomes the only oxidising agent able to react with the carbonaceous matter. 
We investigated the course of activation for two biomass-based substances (glucose and gelatine) by means of thermogravimetric analysis and temperature programmed desorption (TPD) experiments (Figure 2). The thermogravimetric analysis - modification with temperature of the weight loss (TGA) and derivative weight loss (DTG) - of the biomass-based products shows that pyrolysis mainly occurs at temperatures $<500^{\circ} \mathrm{C}$. Specifically, the main weight losses appear below around $400^{\circ} \mathrm{C}$ in the case of glucose (Figure 2a) and $450{ }^{\circ} \mathrm{C}$ in the case of gelatine (Figure $2 \mathrm{~b}$ ). In the case of mixtures of glucose or gelatine with sodium thiosulfate, analysis of the TGA/DTG curves in Figures $2 \mathrm{c}$ and $2 \mathrm{~d}$ allows us to distinguish two regions: a) at temperatures below around $400-450^{\circ} \mathrm{C}$, pyrolysis reactions essentially take place (along with the decomposition of $\mathrm{Na}_{2} \mathrm{~S}_{2} \mathrm{O}_{3}$ ), as can be deduced from the comparison of Figures $2 \mathrm{c}$ and $2 \mathrm{~d}$ with Figures $2 \mathrm{a}$ and $2 \mathrm{~b}$ respectively, and $\mathrm{b}$ ) at higher temperatures, activation reactions dominate the process. Thus, at $\mathrm{T}>400-450$ ${ }^{\circ} \mathrm{C}$, the TGA analysis reveals weight losses not detected for the raw materials alone (Figs. 2a and $2 \mathrm{~b}$ ), which can be ascribed to the reactions between the pyrolyzed products and sulfur compounds (i.e. $\mathrm{Na}_{2} \mathrm{SO}_{4}$ ). Further information is obtained by means of TPD experiments which show the evolution of $\mathrm{CO}$ and $\mathrm{CO}_{2}$ with temperature during the carbonisation-activation of (raw material $/ \mathrm{Na}_{2} \mathrm{~S}_{2} \mathrm{O}_{3}$ ) mixtures (Figures $2 \mathrm{e}$ and $2 \mathrm{f}$ ). During the activation stage (i.e. $>\sim 400-450 \stackrel{\circ}{\circ}$ ), for both raw materials a $\mathrm{CO}_{2}$ peak appears at $\sim 500{ }^{\circ} \mathrm{C}$ which can be associated with reaction (5). At a higher temperature of $\sim 740 \stackrel{\circ}{ } \mathrm{C}$, sharp $\mathrm{CO}_{2}$ and $\mathrm{CO}$ emission peaks can be seen, which suggests both reactions (5) and (6) taking place simultaneously. These results are in agreement with those predicted by the thermodynamic analysis (vide supra). 


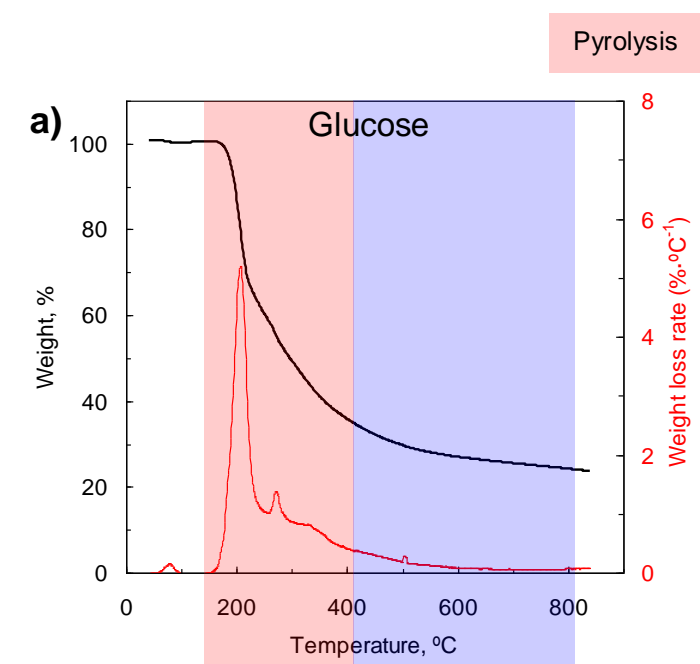

\section{Activation}
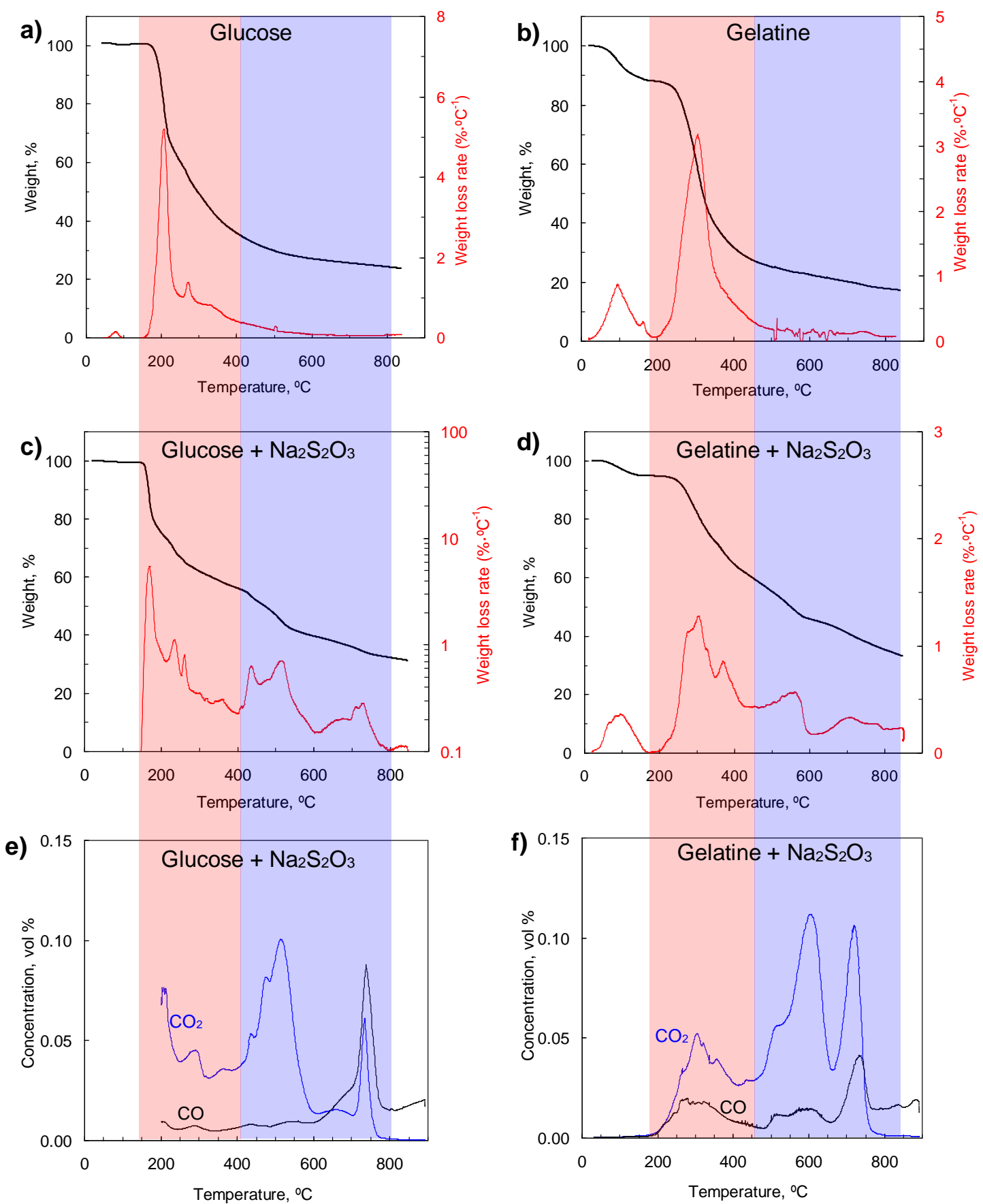

Figure 2. TGA and DTG curves of: (a) glucose, (b) gelatine, (c) glucose $+\mathrm{Na}_{2} \mathrm{~S}_{2} \mathrm{O}_{3}$ and (d) gelatine $+\mathrm{Na}_{2} \mathrm{~S}_{2} \mathrm{O}_{3}$. TPD CO and $\mathrm{CO}_{2}$ emission curves of: (e) glucose $+\mathrm{Na}_{2} \mathrm{~S}_{2} \mathrm{O}_{3}$ and (f) gelatine $+\mathrm{Na}_{2} \mathrm{~S}_{2} \mathrm{O}_{3}$. Heating rate: $5{ }^{\circ} \mathrm{C} \mathrm{min}^{-1}$, atmosphere: nitrogen. 
In relation to this activation process, it is important to point out that the system constituted by $\mathrm{Na}_{2} \mathrm{~S}$ and unreacted $\mathrm{Na}_{2} \mathrm{SO}_{4}$ - present in the reaction medium during activation - forms a liquid phase at temperatures $>740 \stackrel{\circ}{\mathrm{C}}$ (i.e. eutectic point at $28 \% \mathrm{~mol} \mathrm{Na} 2 \mathrm{~S}) .{ }^{42}$ The formation of that liquid phase will have a strong effect on the activation reactions. In fact, at temperatures $\sim 740^{\circ} \mathrm{C}$, the carbonised particles will be wetted by a liquid mixture containing $\mathrm{Na}_{2} \mathrm{SO}_{4}$, which will accelerate redox reactions (5) and (6). ${ }^{43}$ This can explain the intense CO and $\mathrm{CO}_{2}$ emission peaks detected at around $740{ }^{\circ} \mathrm{C}$.
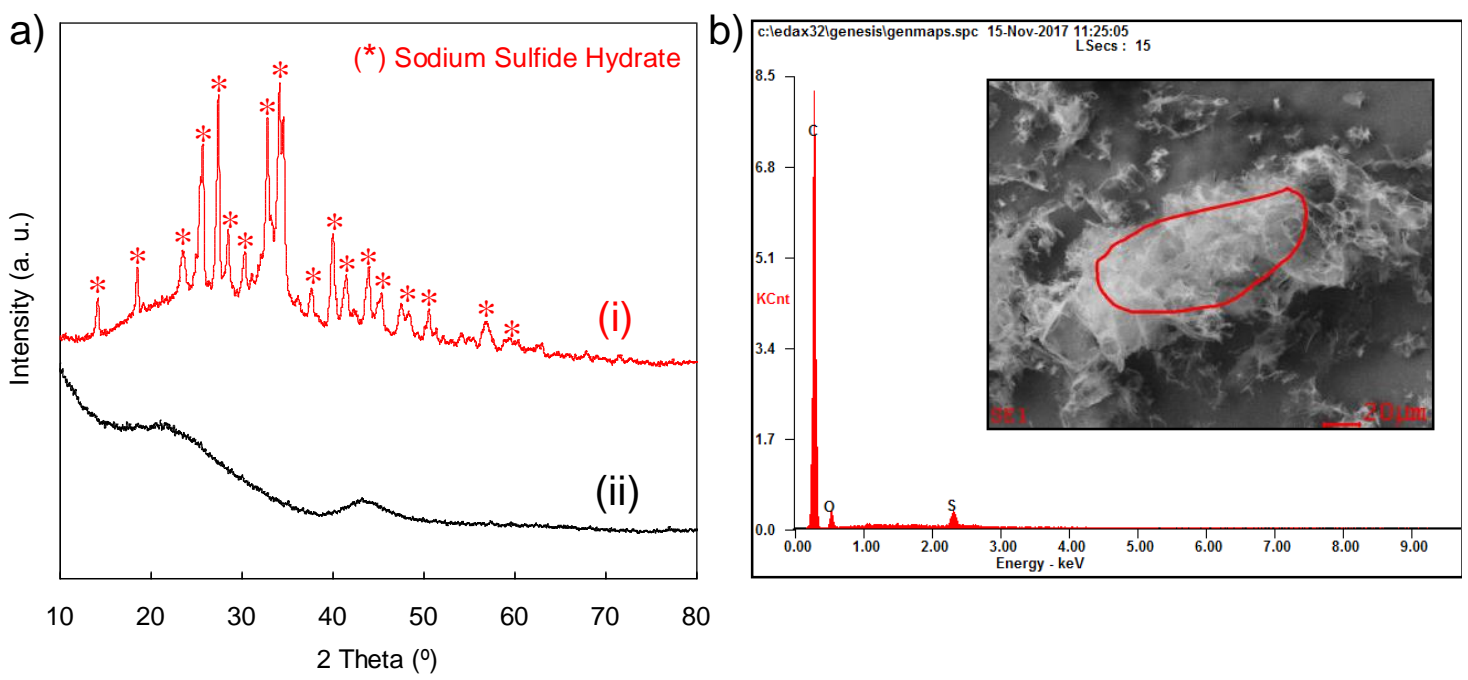

Figure 3. (a) XRD patterns of: (i) solid product obtained after the thermal treatment at $800 \stackrel{\circ}{\circ}$ of a glucose/ $\mathrm{Na}_{2} \mathrm{~S}_{2} \mathrm{O}_{3}$ mixture and (ii) carbon collected after water washing of the carbonised product, and (b) EDX analysis of the porous carbon.

In order to verify the nature of the species present in the activated material, we performed X-ray diffraction analysis of the carbonised product before and after water washing (Figure 3a). The XRD pattern corresponding to the carbonised solid obtained after the thermal treatment shows that sodium sulfate has been completely consumed, and that sodium sulfide is the only inorganic species 
present in the residue. The collected porous carbon, once the solid product is washed with water, exhibits a XRD pattern that contains two low-intensity broad (002) and (100) bands, which are characteristic of carbons with a disordered structure. Interestingly, that carbon does not contain any impurities, as shown by the EDX analysis in Figure 3b, which proves the efficacy of the water washing. The detected S peak corresponds to the sulfur heteroatoms that have been incorporated into the carbon framework during the activation process (vide infra).

\section{Chemical and structural properties of porous carbons}

Our synthesis procedure has been applied to three biomass-based carbon precursors: glucose, sucrose and gelatine. These raw materials were mixed with $\mathrm{Na}_{2} \mathrm{~S}_{2} \mathrm{O}_{3}$ by simple hand grinding. Importantly, the weight ratio $\left(\mathrm{Na}_{2} \mathrm{~S}_{2} \mathrm{O}_{3} /\right.$ precursor) required to obtain good levels of activation are relatively low, in the $0.67-1.3$ range. These values are considerably smaller than those currently used with other chemical activating agents such as $\mathrm{KOH}$, which require high weight ratios, usually $\sim 4$. As noted previously, thermal treatment of the reaction mixture $\left(\mathrm{Na}_{2} \mathrm{~S}_{2} \mathrm{O}_{3} /\right.$ precursor) gives rise to a material composed of porous carbon and sodium sulfide which can be removed simply using water.

The SEM images in Figure S1 for the carbon samples produced in the absence of $\mathrm{KCl}$ reveal that in both cases - glucose (GU-800) (Figures S1a and S1b) and gelatine (GE-800) (Figures S1c and S1d) - the carbon particles consist of two-dimensional and conchoidal structures. The pore structure of these carbons was examined using the nitrogen physisorption method and the

results are displayed in Figure S2 and Table S1. These samples have a porosity made up of almost exclusively narrow micropores (see Figure S2b), 
with BET surface areas of 910 and $1460 \mathrm{~m}^{2} \cdot \mathrm{g}^{-1}$ respectively for the carbons produced from glucose (GU-800) and gelatine (GE-800) (Table S1). The incorporation of an inert salt $(\mathrm{KCl})$ into the reaction mixture produces a notable improvement in the textural properties. Comparison of the $\mathrm{N}_{2}$ adsorption isotherms of both types of carbons clearly reveals that those produced in the presence of $\mathrm{KCl}$ have greater nitrogen uptake (see Figure S2a), both the BET surface area and the pore volumes are significantly higher (see Table S1). For example, whereas for the GE-800 sample $S_{B E T}=1460 \mathrm{~m}^{2} \cdot \mathrm{g}^{-1}$ and $V_{p}=0.66 \mathrm{~cm}^{3} \cdot \mathrm{g}^{-}$ ${ }^{1}$, the carbon synthesised in the presence of $\mathrm{KCl}(\mathrm{GEK}-800)$ has a $\mathrm{S}_{\mathrm{BET}}=2280$ $\mathrm{m}^{2} \cdot \mathrm{g}^{-1}$ and $V_{\mathrm{p}}=1.04 \mathrm{~cm}^{3} \cdot \mathrm{g}^{-1}$. Secondly, the presence of $\mathrm{KCl}$ causes a widening of the pores, as shown by comparison of the PSDs in Figure S2b. Thirdly, the use of $\mathrm{KCl}$ gives rise to a significant increase in carbon yield, which in the case of gelatine increases from $8 \%$ (GE-800) to $19 \%$ (GEK-800). Importantly, the high carbon yields obtained in presence of $\mathrm{KCl}$ are even superior to that corresponding to the simple carbonization of gelatin in absence of activating agents $(\sim 17 \%$ as inferred from Figure $2 b)$. This is a remarkable achievement that evidences the efficiency of this activation methodology based on the employ of sodium thiosulfate.

While the carbonised solids produced without $\mathrm{KCl}$ appear disaggregated, showing notable volumetric expansion, the composite materials synthesised in the presence of $\mathrm{KCl}$ consist of hard black monoliths that do not show any cracks and exhibit significant volumetric contraction in relation to the raw mixture (see Figure S3). The structure of this solid can be identified as a "brick and mortar" system where the melted $\mathrm{Na}_{2} \mathrm{~S}-\mathrm{Na}_{2} \mathrm{SO}_{4}$ mixture is the "mortar" that glues the carbonised precursor and the $\mathrm{KCl}$ particles ("bricks"). The carbonisation and 
activation reactions will occur within the confined space between $\mathrm{KCl}$ particles. Under these circumstances, the release of volatile compounds is severely restricted and a re-deposition of a fraction of the initially emitted gaseous substances will occur, which explains the observed increase in the carbon yield. In addition, the closer interaction between the carbonised products and the activating agent would favour the activation reactions and, in consequence, will lead to an improvement in pore development, as evidenced by the results shown in Figure S2 and in Table S2.

The above results motivated the use of $\mathrm{KCl}$ as a key ingredient in the synthesis mixture. The morphology of the carbons produced in the presence of $\mathrm{KCl}$ is illustrated by the SEM images in Figures 4a-f. They show that the carbon particles have a foam-like structure made up of thin carbon layers. By comparing these microphotographs with those of the carbons produced without $\mathrm{KCl}$ (Figure S1), it can be inferred that this fluffy morphology is a consequence of the presence of the $\mathrm{KCl}$ particles, which have a template effect that determines the macroscopic structure of the carbon particles. Further inspection of the carbon particles produced in presence of $\mathrm{KCl}$ by means of transmission electron microscopy (TEM) reveals a porosity made up of randomly oriented narrow micropores (Figures $4 \mathrm{~g}$ ), whereas the HRTEM image taken at the edge of a carbon particle shows a random agglomeration of curved graphene-like layers, which is characteristic of highly porous carbons (Figure 4h). 

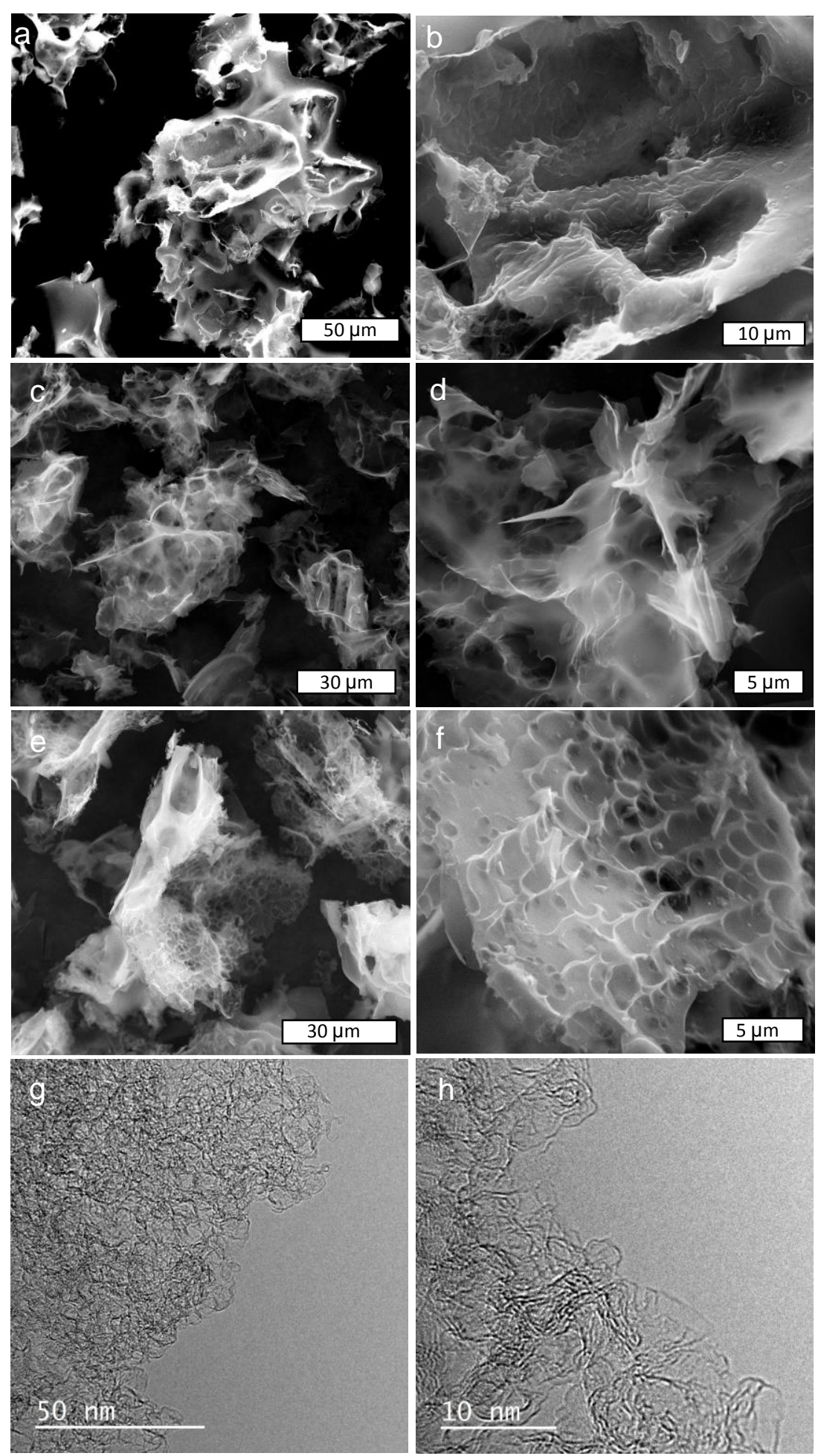

Figure 4. SEM micrographs of the carbon materials produced from: $(a, b)$ gelatine (GEK-800), (c, d) glucose (GUK-800), (e, f) sucrose (SUK-800). (g, h) TEM/HRTEM micrographs of the porous carbon GEK-800-1.3. 
Chemical activation with $\mathrm{Na}_{2} \mathrm{~S}_{2} \mathrm{O}_{3}$ in the presence of $\mathrm{KCl}$ gives rise to highly porous carbons as verified by the nitrogen adsorption analysis. The $\mathrm{N}_{2}$ adsorption isotherms and pore size distributions corresponding to the porous carbons prepared from gelatine are depicted in Figures $5 \mathrm{a}$ and $5 \mathrm{~b}$ respectively. Variations in the shape of the isotherms with the change in temperature, $\left(\mathrm{Na}_{2} \mathrm{~S}_{2} \mathrm{O}_{3} /\right.$ gelatine) weight ratio and mixing method (grinding vs. freeze-drying) denote significant changes in the pore structure of the porous carbons. The isotherms and PSDs obtained for glucose and sucrose are given as Supporting Information in Figures $\mathrm{S} 4 \mathrm{a}$ and $\mathrm{S} 4 \mathrm{~b}$ respectively. Table 1 summarises the values of the textural characteristics of the porous carbons produced from gelatine, glucose and sucrose. They exhibit high BET surface areas up to 2720 $\mathrm{m}^{2} \cdot \mathrm{g}^{-1}$ (GEK-800-1.3-L) and large pore volumes up to $2.4 \mathrm{~cm}^{3} \cdot \mathrm{g}^{-1}$ (GEK-8001.3). All these carbon materials exhibit a porosity made up of two pore systems, one composed of narrow micropores at around $0.8 \mathrm{~nm}$ and the other composed of wider pores in the $1.2-6 \mathrm{~nm}$ range whose size changes depending on the synthesis conditions. These results show that increasing the reaction temperature from $800{ }^{\circ} \mathrm{C}$ to $900{ }^{\circ} \mathrm{C}$ hardly affects the pore structure and only leads to a slight widening of the second micropore system (Figure 5b). By contrast, increasing the $\left(\mathrm{Na}_{2} \mathrm{~S}_{2} \mathrm{O}_{3} /\right.$ gelatine) weight ratio from 0.67 (GEK-800) to 1.3 (GEK-800-1.3) causes substantial changes, with a significant increase in the mesopore volume to $1.67 \mathrm{~cm}^{3} \cdot \mathrm{g}^{-1}$ in the GEK-800-1.3 sample (see Table 1), which is associated with a widening of the second pore system (see Figure 5b). On the other hand, when the reactants are dissolved and freeze-dried (GEK800-1.3-L) instead of grinding (GEK-800-1.3), the resulting porous carbon exhibits a significant increase in the BET surface area $\left(2720 \mathrm{~m}^{2} \cdot \mathrm{g}^{-1}\right.$ for GEK- 
800-1.3-L vs. $2280 \mathrm{~m}^{2} \cdot \mathrm{g}^{-1}$ for GEK-800-1.3) and a notable widening of the mesopores (see Figure 5b).
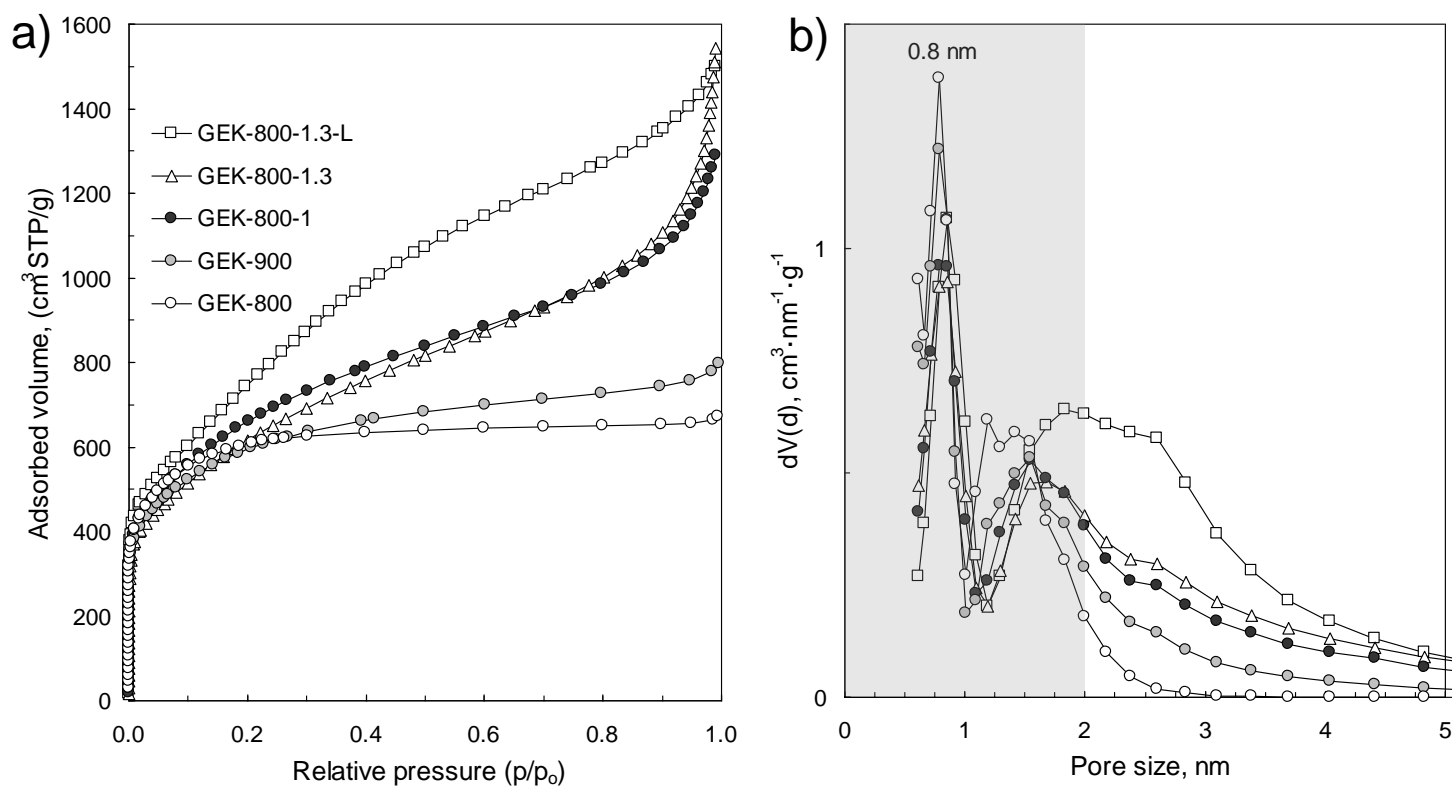

Figure 5. a) Nitrogen sorption isotherms and b) pore size distributions of the porous carbons obtained from gelatine $/ \mathrm{Na}_{2} \mathrm{~S}_{2} \mathrm{O}_{3} / \mathrm{KCl}$ mixtures under different operational conditions. The shaded area in $b$ ) indicates the micropore range.

Table 1. Physico-chemical properties of porous carbons synthesized with the aid of $\mathrm{KCl}$.

\begin{tabular}{|c|c|c|c|c|c|c|c|c|c|}
\hline \multirow{2}{*}{$\begin{array}{l}\text { Carbon } \\
\text { Precursor }\end{array}$} & \multirow{2}{*}{ Sample code } & \multirow{2}{*}{$\begin{array}{l}S_{B E T} \\
\left(m^{2} \cdot g^{-1}\right)\end{array}$} & \multirow{2}{*}{$\begin{array}{l}V_{p} \\
\left(\mathrm{~cm}^{3} \cdot \mathrm{g}^{-1}\right)\end{array}$} & \multirow{2}{*}{$\begin{array}{l}V_{\text {micro }} \\
\left(\mathrm{cm}^{3} \cdot \mathrm{g}^{-1}\right)\end{array}$} & \multirow{2}{*}{$\begin{array}{l}V_{\text {meso }} \\
\left(\mathrm{cm}^{3} \cdot \mathrm{g}^{-1}\right)\end{array}$} & \multirow{2}{*}{$\begin{array}{l}\text { Yield }^{a} \\
(\%)\end{array}$} & \multicolumn{3}{|c|}{ Chem. analysis (wt \%) } \\
\hline & & & & & & & C & $\mathrm{N}$ & S \\
\hline & GEK-800 & 2280 & 1.04 & 0.90 & 0.14 & 19 & 89.9 & 3.30 & 2.73 \\
\hline & GEK-900 & 2130 & 1.23 & 0.82 & 0.41 & 17 & 92.4 & 1.98 & 1.47 \\
\hline \multirow[t]{3}{*}{ Gelatine } & GEK-800-1 & 2390 & 2.0 & 0.83 & 1.17 & 13 & 90.7 & 2.44 & 3.47 \\
\hline & GEK-800-1.3 & 2280 & 2.4 & 0.73 & 1.67 & 11 & 87.0 & 1.84 & 1.93 \\
\hline & GEK-800-1.3-L & 2720 & 2.3 & 0.84 & 1.46 & 12 & 87.1 & 3.23 & 2.60 \\
\hline Glucose & GUK-800 & 2020 & 0.99 & 0.77 & 0.22 & 15 & 91.8 & - & 2.50 \\
\hline Sucrose & SUK-800 & 1900 & 0.96 & 0.76 & 0.20 & - & 86.7 & - & 3.61 \\
\hline
\end{tabular}


During the sodium thiosulfate reaction with the carbon precursor, secondary processes that promote the incorporation of a certain number of sulfur atoms into the carbon framework also take place in addition to the reactions which produce the pores. Chemical analysis of the porous carbons shows that the amount of sulfur incorporated in this way is in the 1.5-3.5 wt \% range (see Table 1). We analysed the chemical nature of the sulfur functional groups by means of X-ray photoelectron spectroscopy (XPS). The highresolution S2p spectrum corresponding to the GEK-800 sample is shown in Figure 6a. It is composed of two doublets, the lower energy and most intense doublet $\left(2 p_{3 / 2}=164.2\right.$ and $\left.2 p_{1 / 2}=165.4 \mathrm{eV}\right)$ being attributable to thiophenic sulfur, C-S-C, and the minor, higher energy doublet (168.1 and $169.3 \mathrm{eV}$ ) to

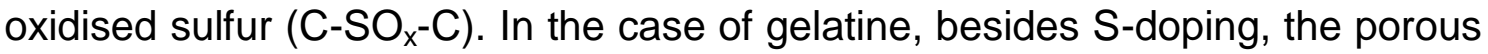
carbons have a certain nitrogen content $(\sim 2-3.3 \mathrm{wt} \%$ as shown in Table 1$)$, coming from the $\mathrm{N}$-rich proteins present in the composition of gelatine. Figure $6 b$ shows the high-resolution N1s XPS spectrum corresponding to the GEK-800 sample. The deconvolution of this signal shows different types of $\mathrm{N}$-groups: i) pyridinic-N (398.5 eV, 19 \%), ii) pyrrolic-/pyridonic-N (400.3 eV, 37 \%), iii) quaternary-N (401.5 eV, 36 \%) and iv) pyridine-N-oxide (403.4 eV, 8 \%), the main two contributions coming from pyrrolic-/pyridonic-N and quaternary- $\mathrm{N}$. 

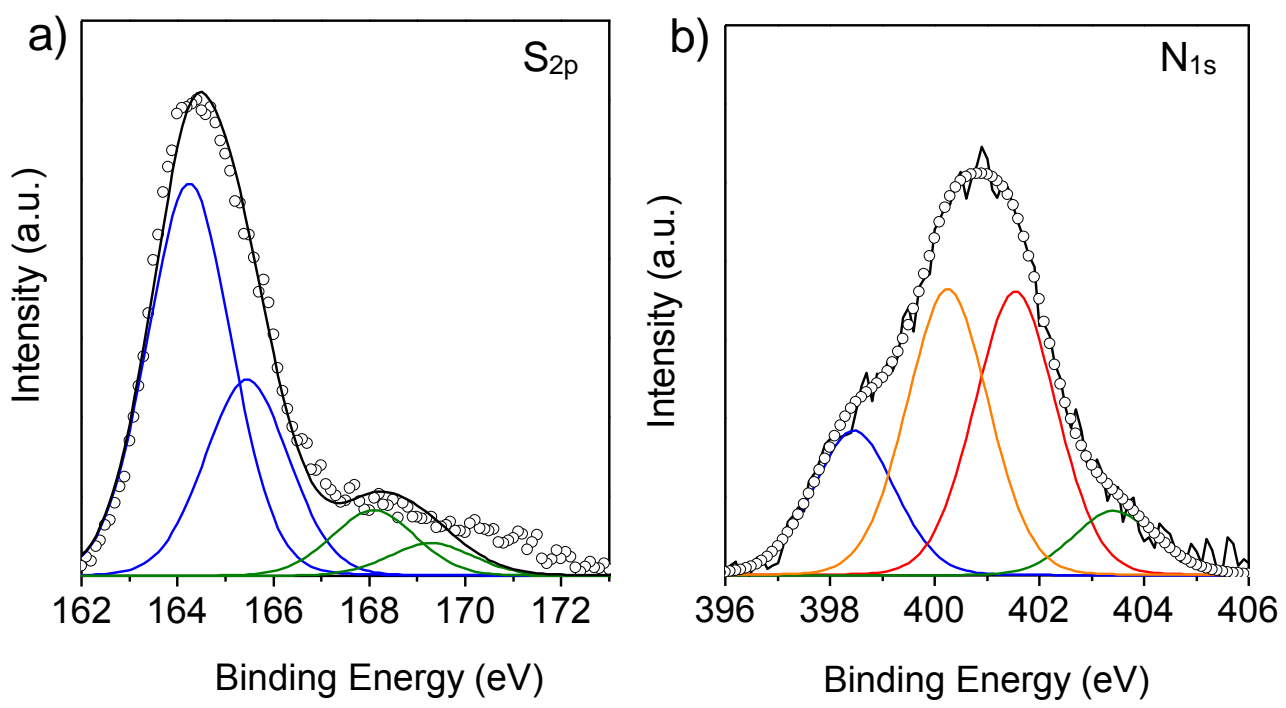

Figure 6. High-resolution XPS spectra of: a) S2p and b) N1s for GEK-800 sample.

It should be emphasised that the production of porous carbons by using sodium thiosulfate as an activating agent has obvious environmental benefits compared to the activation procedures based on inorganic products such as $\mathrm{KOH}$. This is evident from the information in Table 2, which presents a comparative analysis of the hazards associated with the chemical activation processes performed with sodium thiosulfate and with potassium hydroxide. This simple analysis makes it abundantly clear that activation with sodium thiosulfate constitutes a greener approach than the use of potassium hydroxide. Indeed, activation with potassium hydroxide entails significant risks associated not only with the use of this substance, but also the products generated as a consequence of activation (i.e. potassium), as well as the hydrochloric acid needed to purify the carbon material. In addition, at the high reaction temperatures the equipment used in the activation process is attacked by the 
highly corrosive $\mathrm{KOH}$ (melting point of $360^{\circ} \mathrm{C}$ ), which means significant additional operational costs.

Table 2. Comparative analysis of the hazards associated with the activation processes using $\mathrm{Na}_{2} \mathrm{~S}_{2} \mathrm{O}_{3}$ and $\mathrm{KOH}$.

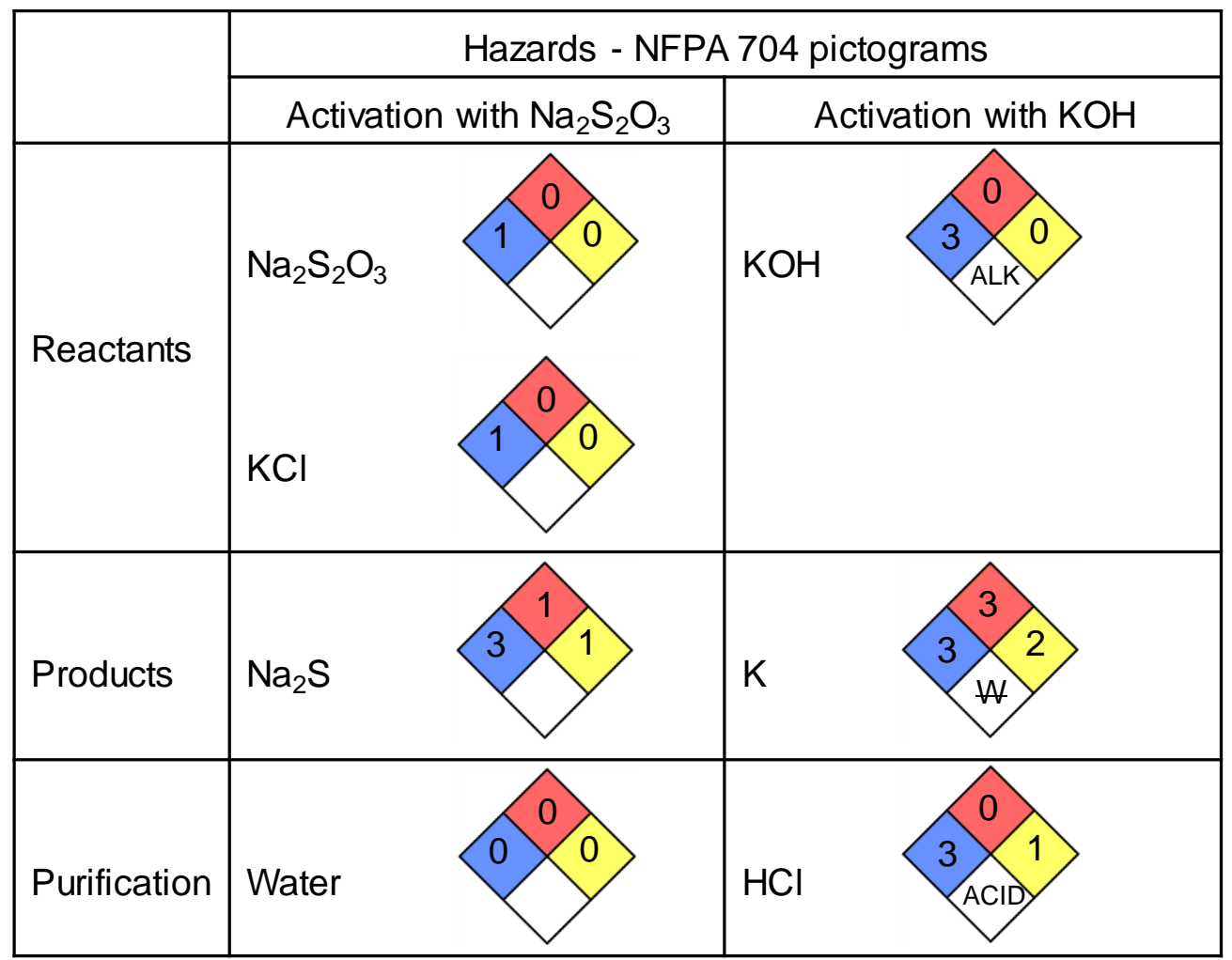

\section{Conclusions}

In summary, a novel and sustainable strategy to produce highly porous carbons has been developed. It is based on the use of affordable, harmless ingredients such as sodium thiosulfate as an activating agent, an inert salt $(\mathrm{KCl})$ as the reaction medium and various biomass-based substances (glucose, sucrose and gelatine) as carbon precursors. The synthesis procedure has three simple steps: a) mixing the reactants by grinding, b) heat treatment at temperatures in the $800-900 \stackrel{\circ}{ } \mathrm{C}$ range and c) collecting the carbon material from the carbonised solid by washing with water. The activation process is mainly 
based on the redox reaction between the carbonaceous material and sodium thiosulfate, which is reduced to sodium sulphide, while $\mathrm{CO}$ and $\mathrm{CO}_{2}$ are generated as a consequence of carbon oxidation. The porous carbons produced in this way have BET surface areas and pore volumes in the $~ 2000$ $2700 \mathrm{~m}^{2} \mathrm{~g}^{-1}$ and $1-2.4 \mathrm{~cm}^{3} \mathrm{~g}^{-1}$ ranges respectively. The porosity of these materials consists of two pore systems; one made up of narrow micropores of $\sim$ $0.8 \mathrm{~nm}$ and the other made up of supermicropores $(0.8-2 \mathrm{~nm})$ and mesopores of up to $5 \mathrm{~nm}$. The porous carbons produced in this way are S-doped $(\sim 2-3 \%)$ as a consequence of secondary reactions between the sulfur compounds and carbon. In addition, the use of $\mathrm{N}$-rich carbon precursors such as gelatine, allows $\mathrm{N}$-doping levels in the $\sim 2-3 \%$ range, which allows the synthesis of N,Scodoped materials.

\section{Notes}

The authors declare no competing financial interest.

\section{Associated Content}

Supporting Information

SEM micrographs, nitrogen adsorption isotherms, pore size distribution and physico-chemical properties of porous carbons prepared with sodium sulfate and in the presence and absence of $\mathrm{KCl}$; picture of the monolithic carbonization product. 


\section{Acknowledgments}

This research work was supported by the Spanish MINECO-FEDER (CTQ201563552-R).

\section{References}

1. Patel, H. A.; Byun, J.; Yavuz, C. T. Carbon Dioxide Capture Adsorbents: Chemistry and Methods. ChemSusChem 2017, 10, 1303-1317.

2. Creamer, A. E.; Gao, B. Carbon-Based Adsorbents for Postcombustion $\mathrm{CO}_{2}$ Capture: A Critical Review. Environ. Sci. Technol. 2016, 50, 7276-7289.

3. Sevilla, M.; Mokaya, R. Energy storage applications of activated carbons: supercapacitors and hydrogen storage. Energy Environ. Sci. 2014, 7, 1250-1280.

4. $\quad$ Yu, X.; Tang, Z.; Sun, D.; Ouyang L.; Zhu, M. Recent advances and remaining challenges of nanostructured materials for hydrogen storage applications. Prog. Mater. Sci. 2017, 88, 1-48.

5. Wang, D. W.; Su, D. Heterogeneous nanocarbon materials for oxygen reduction reaction. Energy Environ. Sci. 2014, 7, 576-591.

6. Wu, K. H.; Wang, D. W.; Su, D. S.; Gentle, I. R. A Discussion on the Activity Origin in Metal- Free Nitrogen- Doped Carbons For Oxygen Reduction Reaction and their Mechanisms. ChemSusChem 2015, 8, 2772-2788.

7. Tang, C.; Zhang, Q. Nanocarbon for oxygen reduction electrocatalysis: dopants, edges, and defects. Adv. Mater. 2017, 29, 1604103.

8. Béguin, F.; Presser, V.; Balducci, A.; Frackowiak, E. Carbons and electrolytes for advanced supercapacitors. Adv. Mater. 2014, 26, 2219-2251.

9. Deng, Y.; Xie, Y.; Zou, K.; Ji, X. Review on recent advances in nitrogen-doped carbons: preparations and applications in supercapacitors. J. Mater. Chem. A 2016, 4, 1144-1173.

10. Wang, H.; Li, Z.; Mitlin, D. Tailoring Biomass- Derived Carbon Nanoarchitectures for High- Performance Supercapacitors. ChemElectroChem 2014, 1, 332-337.

11. Wang, J.; Nie, P.; Ding, B.; Dong, S.; Hao, X.; Dou, H.; Zhang, X. Biomass derived carbon for energy storage devices. J. Mater. Chem. A 2017, 5, 24112428.

12. Marsh, H.; Reinoso, F. R. Activated carbon; Elsevier, 2006.

13. Jenkins, G. M.; Kawamura, K. Polymeric carbons: carbon fibre, glass and char; Cambridge University Press, 1976.

14. McEnaney, B. Properties of Activated Carbons. In Handbook of Porous Solids; Schüth, F., Sing, K. S. W., Weitkamp, J., Eds.; Wiley-VCH Verlag GmbH, Weinheim, Germany, 2002.

15. Ahmadpour, A.; Do, D. The preparation of active carbons from coal by chemical and physical activation. Carbon 1996, 34, 471-479.

16. Dalai, A. K.; Azargohar, R. Production of activated carbon from biochar using chemical and physical activation: Mechanism and modeling. ACS Symposium Series 2007, 954, 463-476. 
17. Rodriguez-Reinoso, F.; Molina-Sabio, M. Activated carbons from lignocellulosic materials by chemical and/or physical activation: an overview. Carbon 1992, 30, 1111-1118.

18. Wang, J.; Kaskel, S. KOH activation of carbon-based materials for energy storage. J. Mater. Chem. 2012, 22, 23710-23725.

19. Borchardt, L.; Oschatz, M.; Kaskel, S. Carbon materials for lithium sulfur batteries-Ten critical questions. Chem. Eur. J. 2016, 22, 7324-7351.

20. Li, S.; Jin, B.; Zhai, X.; Li, H.; Jiang, Q. Review of Carbon Materials for Lithium- Sulfur Batteries. ChemistrySelect 2018, 3, 2245-2260.

21. Eftekhari, A.; Kim, D.-W. Cathode materials for lithium-sulfur batteries: a practical perspective. J. Mater. Chem. A 2017, 5, 17734-17776.

22. Li, Z.; Huang, Y.; Yuan, L.; Hao, Z.; Huang, Y. Status and prospects in sulfurcarbon composites as cathode materials for rechargeable lithium-sulfur batteries. Carbon 2015, 92, 41-63.

23. Gu, X.; Hencz, L.; Zhang, S. Recent development of carbonaceous materials for lithium-sulphur batteries. Batteries 2016, 2, 33.

24. Zhang, J.; Huang, H.; Bae, J.; Chung, S. H.; Zhang, W.; Manthiram, A.; Yu, G. Nanostructured Host Materials for Trapping Sulfur in Rechargeable Li-S Batteries: Structure Design and Interfacial Chemistry. Small Methods 2018, 2, 1700279.

25. Park, J.; Yu, S.H.; Sung, Y.E. Design of structural and functional nanomaterials for lithium-sulfur batteries. Nano Today 2018, 18, 35-64.

26. Hayashi, J.; Horikawa, T.; Takeda, I.; Muroyama, K.; Ani, F. N. Preparing activated carbon from various nutshells by chemical activation with $\mathrm{K}_{2} \mathrm{CO}_{3}$. Carbon 2002, 40, 2381-2386.

27. Sun, Y.; Yang, G.; Wang, Y. S.; Zhang, J. P. Production of activated carbon by $\mathrm{K}_{2} \mathrm{CO}_{3}$ activation treatment of furfural production waste and its application in gas storage. Environ. Prog. Sustain. Energy 2011, 30, 648-657.

28. Sun, Y.; Webley, P. A. Preparation of Activated Carbons with Large Specific Surface Areas from Biomass Corncob and Their Adsorption Equilibrium for Methane, Carbon Dioxide, Nitrogen, and Hydrogen. Ind. Eng. Chem. Res. 2011, 50, 9286-9294.

29. Mestre, A. S.; Freire, C.; Pires, J.; Carvalho, A. P.; Pinto, M. L. High performance microspherical activated carbons for methane storage and landfill gas or biogas upgrade. J. Mater. Chem. A 2014, 2, 15337-15344.

30. Deng, J.; Xiong, T.; Xu, F.; Li, M.; Han, C.; Gong, Y.; Wang, H.; Wang, Y. Inspired by bread leavening: one-pot synthesis of hierarchically porous carbon for supercapacitors. Green Chem. 2015, 17, 4053-4060.

31. Sevilla, M.; Fuertes, A. B. A Green Approach to High- Performance Supercapacitor Electrodes: The Chemical Activation of Hydrochar with Potassium Bicarbonate. ChemSusChem 2016, 9, 1880-1888.

32. Sevilla, M.; Ferrero, G. A.; Fuertes, A. B. One-Pot Synthesis of Biomass-Based Hierarchical Porous Carbons with a Large Porosity Development. Chem. Mater. 2017, 29, 6900-6907.

33. Sevilla, M.; Al-Jumialy, A. S. M.; Fuertes, A. B.; Mokaya, R. Optimization of the Pore Structure of Biomass-Based Carbons in Relation to Their Use for $\mathrm{CO}_{2}$ Capture under Low- and High-Pressure Regimes. ACS Appl. Mater. Interfaces 2018, 10, 1623-1633.

34. Sevilla, M.; Ferrero, G. A.; Fuertes, A. B. Beyond KOH activation for the synthesis of superactivated carbons from hydrochar. Carbon 2017, 114, 50-58. 
35. Sevilla, M.; Fuertes, A. B. A general and facile synthesis strategy towards highly porous carbons: carbonization of organic salts. J. Mater. Chem. A 2013, 1, 13738-13741.

36. Ferrero, G. A.; Fuertes, A. B.; Sevilla, M.; Titirici, M. M. Efficient metal-free N-doped mesoporous carbon catalysts for ORR by a template-free approach. Carbon 2016, 106, 179-187.

37. Ferrero, G. A.; Sevilla, M.; Fuertes, A. B. Mesoporous carbons synthesized by direct carbonization of citrate salts for use as high-performance capacitors. Carbon 2015, 88, 239-251.

38. Liu, X.; Antonietti, M. Moderating black powder chemistry for the synthesis of doped and highly porous graphene nanoplatelets and their use in electrocatalysis. Adv. Mater. 2013, 25, 6284-6290.

39. Hayashi, J.; Kazehaya, A.; Muroyama, K.; Watkinson, A. P. Preparation of activated carbon from lignin by chemical activation. Carbon 2000, 38, 18731878.

40. Linares-Solano, A.; Lozano-Castello, D.; Lillo-Ródenas, M.; Cazorla-Amorós, D. Carbon activation by alkaline hydroxides preparation and reactions, porosity and performance. In Chemistry and Physics of Carbon, vol. 30; Radovic, L.R., Ed.; CRC Press, Boca Raton, 2008.

41. Liu, X.; Antonietti, M.; Molten salt activation for synthesis of porous carbon nanostructures and carbon sheets. Carbon 2014, 69, 460-466.

42. Tran, H. N.; Barham, D. Presented at International Conference on the Recovery of Chemical, Vancouver, British Columbia, September, 1981.

43. White, J. F.; White, A. H. Manufacture of Sodiym Sulfide: Reduction of Sodium sulfate to Sodium Sulfide at Temperatures below $800^{\circ} \mathrm{C}$. Ind. Eng. Chem. 1936, 28, 244-246. 


\section{For Table of Contents Use Only}

A green route to highly porous carbons by using sodium thiosulfate as activating agent and biomass-based products as carbon precursors is presented.
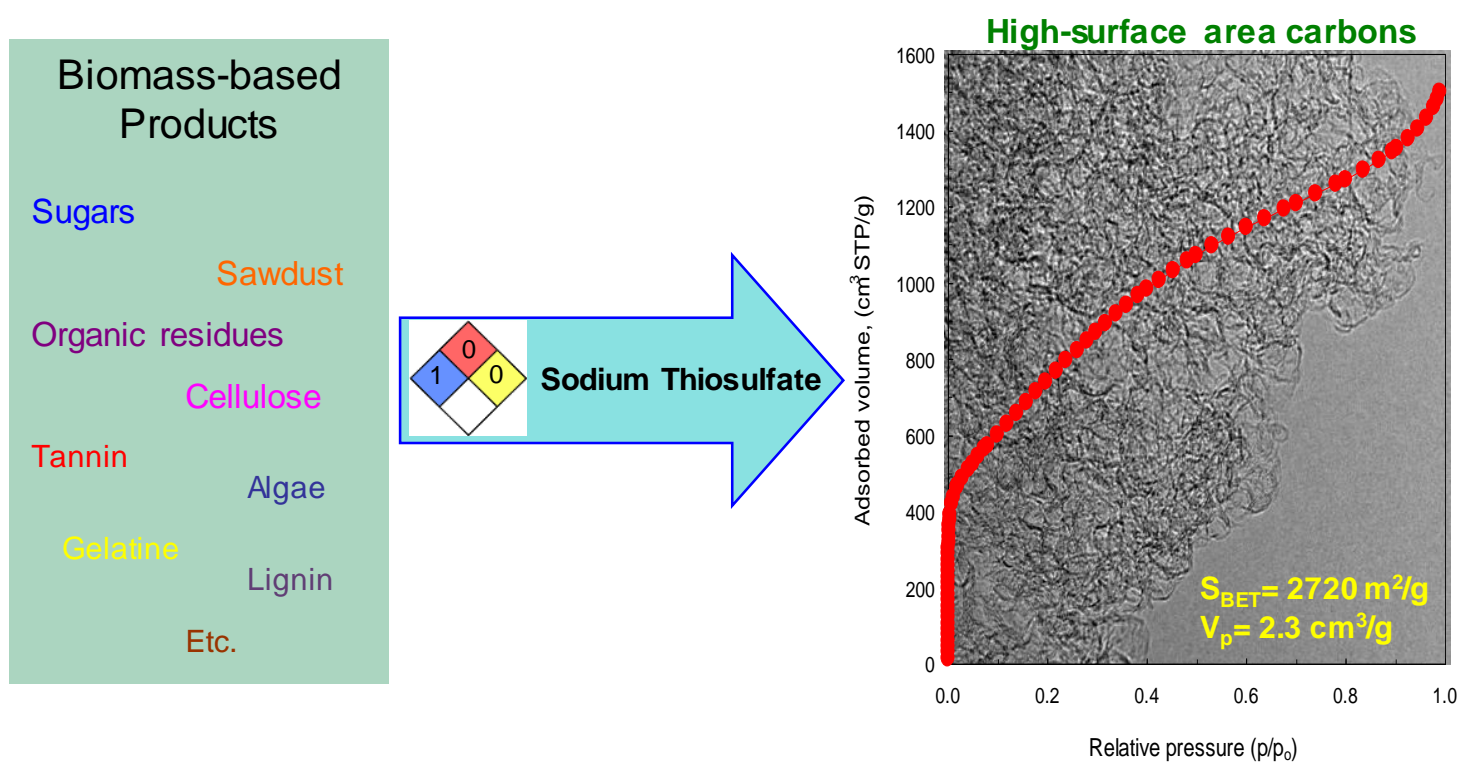